\title{
Basal forebrain thermoregulatory mechanism modulates auto-regulated sleep
}

\author{
Hruda Nanda Mallick ${ }^{1}$ and Velayudhan Mohan Kumar ${ }^{2}$ \\ 1 Department of Physiology, All India Institute of Medical Sciences, New Delhi, India \\ ${ }^{2}$ Comprehensive Centre for Sleep Disorders, Sree Chitra Tirunal Institute for Medical Science and Technology, Thiruvananthapuram, Kerala, India
}

\author{
Edited by: \\ V. Mohan Kumar, Sree Chitra Tirunal \\ Institute for Medical Sciences and \\ Technology, India \\ Reviewed by: \\ Bindu M. Kutty, National Institute of \\ Mental Health and Neurosciences, \\ India \\ Kamalesh K. Gulia, Sree Chitra Tirunal \\ Institute for Medical Sciences and \\ Technology, India \\ *Correspondence: \\ Hruda Nanda Mallick, Department of \\ Physiology, All India Institute of \\ Medical Sciences, New Delhi 110029, \\ India. \\ e-mail:drhmallick@yahoo.com
}

Regulation of body temperature and sleep are two physiological mechanisms that are vital for our survival. Interestingly neural structures implicated in both these functions are common. These areas include the medial preoptic area (POA), the lateral POA, the ventrolateral POA, the median preoptic nucleus, and the medial septum, which form part of the basal forebrain (BF). When given a choice, rats prefer to stay at an ambient temperature of $27^{\circ} \mathrm{C}$, though the maximum sleep was observed when they were placed at $30^{\circ} \mathrm{C}$. Ambient temperature around $27^{\circ} \mathrm{C}$ should be considered as the thermoneutral temperature for rats in all sleep studies. At this temperature the diurnal oscillations of sleep and body temperature are properly expressed. The warm sensitive neurons of the POA mediate the increase in sleep at $30^{\circ} \mathrm{C}$. Promotion of sleep during the rise in ambient temperature from 27 to $30^{\circ} \mathrm{C}$, serve a thermoregulatory function. Autonomous thermoregulatory changes in core body temperature and skin temperature could act as an input signal to modulate neuronal activity in sleep-promoting brain areas. The studies presented here show that the neurons of the $\mathrm{BF}$ play a key role in regulating sleep. BF thermoregulatory system is a part of the global homeostatic sleep regulatory mechanism, which is auto-regulated.

Keywords: ambient temperature, thermal preference, sleep, thermoregulation, basal forebrain, preoptic area, thermoreceptors, thermoneutral zone

\section{INTRODUCTION}

Vigilance states in mammals pass through cyclic alterations between wake and sleep states. These alterations involve extensive changes in physiological functions. A fundamental behavior like sleep-wakefulness is organized at all levels of the neuraxis. The induction, maintenance and timing of wake, non-rapid eye movement sleep (NREM) or slow wave sleep (SWS), and rapid eye movement (REM) sleep are the products of complex interactions among multiple structures and mechanisms which are widely distributed throughout the brain. According to the classical concept, reciprocal interaction between sleep and wake promoting systems ensures that the behavioral state of sleep-wakefulness is altered as per requirement. Prominent among these sleep-promoting structures are the pontine tegmentum and adjacent neuronal groups involved in the generation of REM sleep features. On the other hand the NREM sleep is promoted by several areas including the medial preoptic area (mPOA), the lateral preoptic area (IPOA), the ventrolateral preoptic area (vlPOA), the median preoptic nucleus ( $\mathrm{mnPO}$ ), and the medial septum, which are referred to as basal forebrain (BF) areas (Sherin et al., 1996; John and Kumar, 1998; Gong et al., 2000; Lu et al., 2000; Srividya et al., 2004, 2006).

There are external and internal factors that influence the swing of sleep-wakefulness toward either sleep or awake state. Several internal signals, including sleep inducing substances, are sleep facilitating (Hayaishi, 1991; Porkka-Heiskanen et al., 1997). BF should be considered as part of the neural mechanism through which many of these internal signals act. There is enough evidence to suggest that they integrate sleep with body temperature, hunger, thirst, circadian cycles, neuroendocrine outputs, homeostatic mechanisms, autonomic responses, and stereotyped behavior (Kumar, 2010). The BF plays a strategic role in integrating thermoregulation and sleep regulation. Way back in 2005 it was suggested that the circadian modulation of body temperature is possibly involved in altering sleep propensity (Kumar, 2005). Since then several findings have emerged which have given us enough evidences to state with confidence that the thermoregulatory mechanism modulates the auto-regulated sleep. The present review focuses on the influence of the BF thermoregulatory mechanism on sleep-wakeful state, which ultimately brings about the intimate complementary homeostatic regulation of these two important physiological functions.

\section{THERMOREGULATION}

Body temperature regulation is a fundamental homeostatic function that is regulated by the central nervous system in all homeotherms including man. The POA is considered as the most important thermoregulatory site in the brain on the basis of thermoregulatory responses elicited by local warming and cooling, lesion, stimulation and single neuronal recording, and many other techniques (Nakayama et al., 1961, 1963; Boulant and Hardy, 1974; Boulant, 1981; Boulant and Dean, 1986). Local cooling of the POA evokes non-shivering thermogenesis as well as shivering thermogenesis (Hammel, 1960; Imai-Matsumura et al., 1984). Local warming evokes cutaneous vasodilatation as well as salivary secretion in rats (Kanosue et al., 1990, 1994). The thermosensitive neurons in the POA receive and integrate cutaneous and deep body 
thermal information. These neurons are tonically active at thermoneutral temperature, and control the thermoregulatory efferent pathway (Nakayama et al., 1961, 1963). Lesion studies in rats had provided information that proved invaluable in the understanding of the thermoregulatory function of the BF. After selective destruction of the POA neurons (using local injection of NMDA) there was an increase in body temperature (Kumar et al., 1996; John and Kumar, 1998; Kumar, 1999, 2005). This hyperthermia produced by the NMDA lesion of the POA was without impaired heat defense abilities (Kumar and Khan, 1998). The POA neuronal lesion produced an increase in the range of thermostat setting, rather than a failure in thermoregulation per se. In other words, the POA is important for regulating body temperature at the "set temperature." On the other hand, classical electrolytic lesion of the POA that destroys neurons and fibers, produces drastic deficit in thermoregulation (Szymusiak and Satinoff, 1982). One can conclude that several other structures, including those fibers are connecting or passing through the POA, would be playing a major role in thermoregulation.

\section{SLEEP REGULATION}

The existence of sleep-wake promoting areas in the brain was first indicated by von Economo. Post-mortem examination of the brains of Encephalitis lethargica patients with hypersomnolence showed that they had lesions at the junction of the midbrain and the diencephalon (von Economo, 1930). On the other hand, some patients with lesion in the anterior hypothalamic-POA (POAH) had insomnia. The concept of the POA as a sleep-promoting area and the posterior hypothalamus as the wake promoting area was supported by several lines of animal experiments employing stimulation, lesion, single unit recording, neural transplantation, functional magnetic resonance imaging (fMRI), and c-fos studies (Nauta, 1946; Sterman and Clemente, 1962; McGinty and Sterman, 1968; Szymusiak and McGinty, 1986; John et al., 1994, 1998; Sherin et al., 1996; John and Kumar, 1998; Khubchandani et al., 2005). Electrical stimulation of BF was shown to produce drowsiness followed by natural behavioral and electroencephalographic sleep (Sterman and Clemente, 1962). Conversely large lesions of these areas resulted in decrease in sleep and disruption of sleep cycle (Szymusiak and Satinoff, 1982). Neurons that increase their overall rate of discharge during SWS were found in the BF. Clinical evidence and experimentations over the last 80 years have led to the prevailing hypothesis that BF has SWS promoting or hypnogenic structures. More recently, sleep active neurons have been found to be concentrated in the vlPOA and mnPO (Gong et al., 2000; Lu et al., 2000). The importance of these cell groups is evident from c-fos expression during sleep state (Sherin et al., 1996).

\section{AMBIENT TEMPERATURE AND SLEEP}

Apart from the subconscious mechanisms for body temperature control, the body has yet another temperature-controlling mechanism that is even more potent. This is the behavioral control of temperature. Whenever the internal body temperature becomes too high, signals from the brain temperature-controlling areas give the person a psychic sensation of being overheated. Conversely, whenever the body becomes cold, signals from the skin, and from the deep body receptors, elicit the feeling of cold discomfort.
Therefore, the person makes appropriate environmental adjustments to re-establish comfort. Indeed, for man, this is the only really effective mechanism for body heat control in severely cold environment. But to study the neural mechanism involved in these regulations and interrelation we depend a lot on the information obtained from lower animals.

It was shown in cats that the sleep was maximal at thermoneutral zone (TNZ) and that it decreases above and below TNZ (Parmeggiani et al., 1969). Subsequently several reports showed that the ambient temperature $\left(T_{\mathrm{amb}}\right)$ produces complex changes in both NREM/SWS and REM sleep. The changes in sleep-wakefulness were studied in rats when they were exposed to different ambient temperature of 18,24 , and $30^{\circ} \mathrm{C}$ (Thomas and Kumar, 2000). There was an increase in REM sleep and SWS, and a decrease in wakefulness at higher ambient temperature of $30^{\circ} \mathrm{C}$. Even chronic exposure to $30^{\circ} \mathrm{C}$ produced persistent increase in REM sleep (Mahapatra et al., 2005). The increase in sleep was primarily due to an increase in the duration of sleep episodes. According to one report on rats, NREM sleep and the metabolic rate were not affected much in between 23 and $31^{\circ} \mathrm{C}$. However, the amount of REM sleep was at its peak at $29^{\circ} \mathrm{C}$, and a marked decrease occurred at $33^{\circ} \mathrm{C}$ (Szymusiak and Satinoff, 1981).

Exposure of rats to gradual increase in ambient temperature from 18 to $30^{\circ} \mathrm{C}$ produces a linear increase in the percentage of REM sleep (Szymusiak and Satinoff, 1984; Thomas and Kumar, 2000; Kumar et al., 2009). The increase in the amount of sleep may be considered as an adaptation to thermal load aimed at energy conservation (Obal et al., 1983). It is interesting to note that REM sleep is influenced by ambient temperature even within TNZ. When human subjects were exposed to a range of ambient temperature, total sleep time (TST), NREM, and REM sleep were maximal at $29^{\circ} \mathrm{C}$ (Haskell et al., 1981). But when they were exposed to $T_{\mathrm{amb}}$ of $35^{\circ} \mathrm{C}$, there was fragmented sleep with decrease in TST and increase in wakefulness, without any change in REM or delta sleep (Libert et al., 1988). Moreover, heat was found to be more potent as a sleep disruptor than noise (Libert et al., 1991).

Sleep is reduced when the $T_{\mathrm{amb}}$ is lowered (Parmeggiani and Rabini, 1970; Schmidek et al., 1972; Szymusiak and Satinoff, 1984; Alföldi et al., 1990; Rosenthal and Vogel, 1991; Ray et al., 2004). In rats, there is a linear decrease in the percentage of REM sleep from 24 to $10^{\circ} \mathrm{C}$ (Valatx et al., 1973; Alföldi et al., 1990; Kumar et al., 2009). Though the REM sleep is more sensitive to ambient temperature changes, SWS is also decreased at low ambient temperature. The TST, SWS, and REM sleep are decreased in rats when they are exposed to $T_{\mathrm{amb}}$ of $18 \pm 1^{\circ} \mathrm{C}$ for a few hours (Thomas and Kumar, 2000; Mahapatra et al., 2005). It was suggested that the central nervous system calls for an increase in the amount of arousal, at the expense of the sleep stages, especially REM sleep, in order to maintain the body temperature $\left(T_{\mathrm{b}}\right)$ when the $T_{\mathrm{amb}}$ is low (Parmeggiani and Rabini, 1970; Alföldi et al., 1990). An increase in arousal in cold $T_{\mathrm{amb}}$ is necessary for the production of more heat (Schmidek et al., 1972; Parmeggiani et al., 1975). In other words, the functional state of wakefulness enables the organism to optimize thermoregulation. The central thermoreceptors have also been shown to activate non-shivering thermogenesis (Chen et al., 1998). 


\section{THERMONEUTRAL TEMPERATURE AND SLEEP}

As sleep is said to be influenced by $T_{\mathrm{amb}}$ and the REM sleep is said to vary within the TNZ, it is important to address the question of TNZ for small animals. According to the first edition of the Glossary of Terms by the Commission for Thermal Physiology of the International Union of Physiological Sciences (Bligh and Johnson, 1973), TNZ is defined as "The range of $T_{\text {amb }}$ within which metabolic rate is at a minimum, and within which temperature regulation is achieved by non-evaporative physical processes alone." Many methods have been used to determine the TNZ in various animals. The TNZ for laboratory animals described in the literature, based on minimal metabolic activity, maximal REM sleep, or the preferred temperature, are wide and contradictory. The most widely used method, i.e., minimum metabolic rate, has found the TNZ to be between 18 and $28^{\circ} \mathrm{C}$ (Poole and Stephenson, 1977). Many others have described a range of $28-34^{\circ} \mathrm{C}$ (Herrington, 1940; Clarkson et al., 1972; Gordon, 1987). According to another definition, the TNZ is "the range of $T_{\mathrm{amb}}$ at which temperature regulation is achieved only by control of sensible heat loss." Based on this the TNZ for Wistar rats have been reported to be between 29.5 and $30.5^{\circ} \mathrm{C}$ (Romanovsky et al., 2002). Thus the suggested TNZ from all these studies vary from 18 to $34^{\circ} \mathrm{C}$. Such contradictions described above emphasize that the TNZ for a given species, as determined by using a particular technique, is of little help in selecting the $T_{\mathrm{amb}}$ for another study using a different variable. Therefore, before determining the responses to $T_{\mathrm{amb}}$ on sleep, it makes sense to determine the TNZ of the animal using the behavioral criteria. One of the convenient methods is to study the preferred temperature (thermal preferendum) of the animal. Thermal preference has been traditionally studied in a thermogradient, or thermocline. Thermogradient is a narrow metallic tube inside which, the animal stays in contact with thermoconductive floor and walls and is exposed to a unique, highly hetero-thermal radiant field. The thermal environment inside these devices is drastically different from the animal's typical home cage. Even the heat exposure at head and tail are different in this device. The animal cannot also indulge in its normal exploratory activity without going into uncomfortable $T_{\mathrm{amb}}$. Therefore an environmental chamber was designed to allow free movement of the animal in an environment resembling home cage (Figure 1). The advantages of the chamber are that: (i) it allows free movement of the animal from one chamber to another; (ii) the entire animal is exposed to a particular temperature; (iii) each chamber is similar to the others except for the $T_{\mathrm{amb}}$; (iv) all chambers have home cage environment with husk, food, and water bottle; (v) the vibration sensitive base of the chambers allows instrumental (automatic) recording of the time spent in each chamber; (vi) the vibration sensitive base allows recording of the activity of the animal at each thermal environment; (vii) animal has the freedom to retrace its step, if it goes to an environment that is not preferred; (viii) using telemetric recording devices, sleep and body temperature of the animal can be recorded along with its thermal preference; and (ix) these chambers are sound attenuated to prevent distraction by external noise. Three different sets of temperatures (first set: 18,24 , and $27^{\circ} \mathrm{C}$; second set: 24,27 , and $30^{\circ} \mathrm{C}$; and third set: 27,30 , and $33^{\circ} \mathrm{C}$ ) were employed to study the thermal preference while looking into the influence of $T_{\mathrm{amb}}$ on sleep architecture. Using this chamber it was found that the rats preferred to stay at $27^{\circ} \mathrm{C}$, while the maximum sleep was obtained at $29-30^{\circ} \mathrm{C}$ (Ray et al., 2004, 2005; Kumar et al., 2009, 2012).

The temperature at which REM sleep is maximal is sometimes considered as TNZ by some scientists (Szymusiak and Satinoff, 1981). The underlying assumption is that the animal goes into

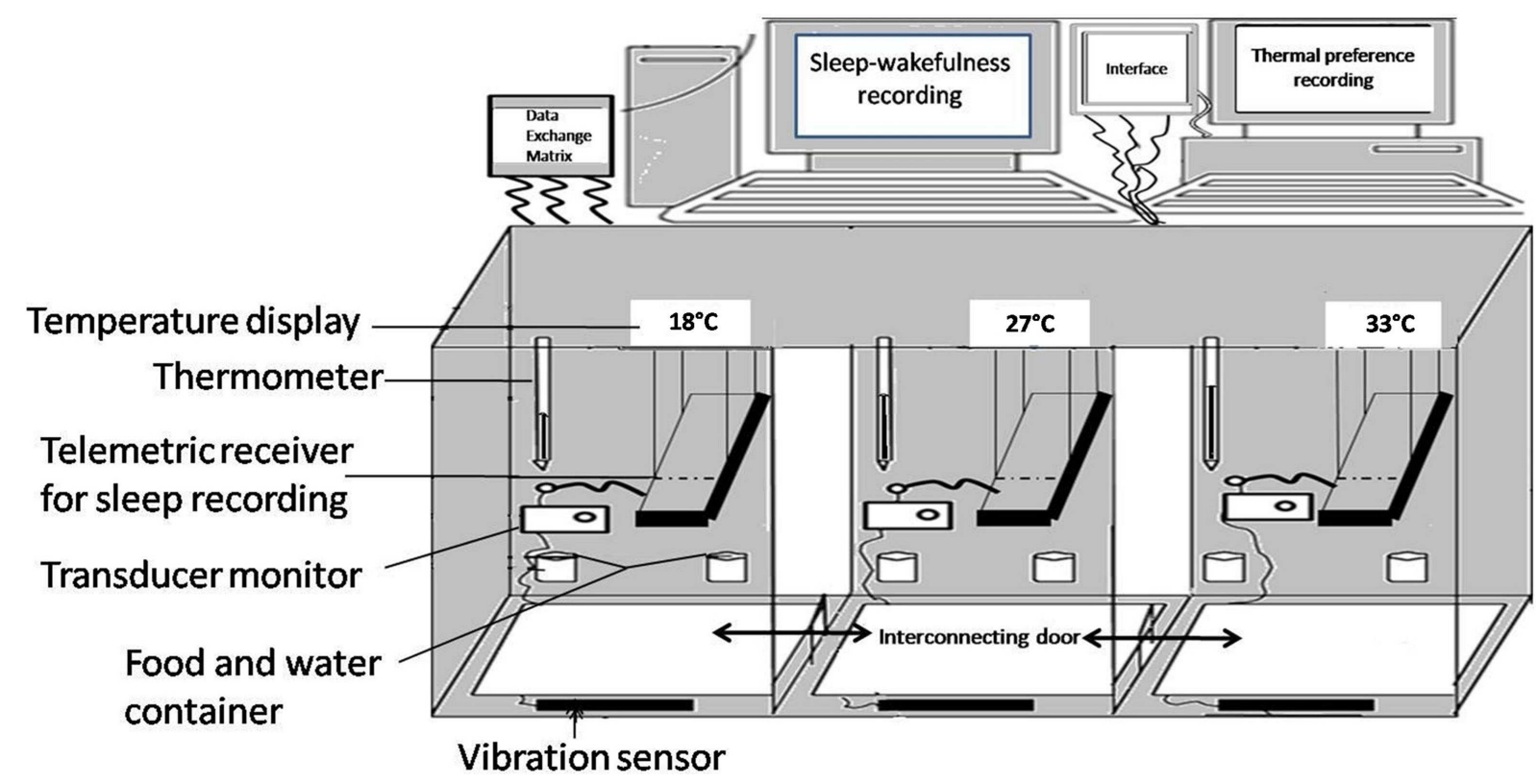

FIGURE 1 | Schematic diagram of environmental chamber having three different ambient temperature $\left(18,30\right.$, and $\left.33^{\circ} \mathrm{C}\right)$ in the three interconnected compartments. 
REM sleep only when internal and external conditions, including thermal environment, are the most favorable. Based on this definition of $\mathrm{TNZ}, 30^{\circ} \mathrm{C}$ is considered as thermoneutral temperature for Wistar rats (Romanovsky et al., 2002). Monitoring of body temperature $\left(T_{\mathrm{b}}\right)$ along with sleep-wakefulness at different $T_{\text {amb }}$ showed that behavioral criteria should be given due importance while looking for TNZ for sleep studies (Kumar et al., 2009). Sleep-wakefulness recordings during the day time in the nocturnal rats showed that the sleep followed a bell-shaped distribution, with a maximum during 11:00-15:00 hours (Figure 2). The $T_{\mathrm{b}}$, on the other hand, showed a reversed bell-shaped curve. The trough of $T_{\mathrm{b}}$ curve could be attributed to diurnal influence and sleeprelated change (Obal et al., 1985; Alföldi et al., 1990; Baker et al., 2005). The $T_{\mathrm{b}}$ trough disappeared at $30^{\circ} \mathrm{C}$, though maximal REM sleep was recorded at the $T_{\mathrm{amb}}$ of $30^{\circ} \mathrm{C}$. The increased sleep at around the $T_{\mathrm{amb}}$ of $30^{\circ} \mathrm{C}$ may be a response to thermal load aimed at energy conservation (Obal et al., 1983). It was seen that the increase in thermal load at $30^{\circ} \mathrm{C}$ attenuated the diurnal lowering of $T_{\mathrm{b}}$. The ability to oppose diurnal shift in the $T_{\mathrm{b}}$ resides in the POA, as the lesion of this area produced higher diurnal change in the $T_{\mathrm{b}}$ in golden hamsters (Osborne and Refinetti, 1995). The POA could be involved in fine-tuning the body temperature to regulate sleep as per the requirement (Thomas and Kumar, 2002; Kumar, 2005).

Though the maximum sleep was recorded at $30^{\circ} \mathrm{C}$, the thermoregulatory diurnal oscillation was least disturbed only at $27^{\circ} \mathrm{C}$ $T_{\mathrm{amb}}$. So, $T_{\mathrm{amb}}$ around $27^{\circ} \mathrm{C}$, which is preferred by the rats, where the diurnal oscillations of these parameters are properly expressed, should be considered as the TNZ for rats. It should also be kept in mind that $T_{\mathrm{amb}}$ that is comfortable for sleep may not be comfortable for activity during wakeful period.
INFLUENCE OF BODY AND BRAIN TEMPERATURE ON SLEEP

Stimulation of central thermoreceptors by circulating blood temperature is likely to be an important source of impulses driving sleep inducing structures of BF (Moruzzi, 1972). Body and brain temperatures of rats are increased by more than $1^{\circ} \mathrm{C}$ when the ambient temperature is increased from 21 to $29^{\circ} \mathrm{C}$ (Alföldi et al., 1990). This increase in body and brain temperatures may be responsible for the increase in SWS/NREM in animals and human subjects at warm $T_{\mathrm{amb}}$ (Horne and Staff, 1983; Horne and Shackell, 1987; Shapiro et al., 1989; McGinty and Szymusiak, 1990; Morairty et al., 1993). This possibility is supported by the observation that local warming of the POA using chronically implanted water perfused thermode triggered SWS or EEG slow wave activity in rats, rabbits, and cats (McGinty and Szymusiak, 2003). In kangaroo rats SWS could be tonically increased for several hours during continuous warming of the POA (Sakaguchi et al., 1979). Delta activity is also increased during this sustained SWS. Sustained increase in delta activity supports a hypothesis that sleep drive is modulated by thermosensitive neurons of the POA. On the other hand, both SWS and REM sleep were suppressed by mild cooling of the POA.

Warm sensitive neurons (WSN) and cold sensitive neurons (CSN) have been identified in the POA on the basis of in vivo and in vitro studies (Nakayama et al., 1961, 1963). These neurons are identified on the basis of responses to local warming or cooling. Most WSN are sleep active, whereas CSN are wake active. The activities of posterior hypothalamic neurons, dorsal raphe in the midbrain, lateral hypothalamic orexinergic neurons, and BF cholinergic neurons are inhibited by the POA warming (Krilowicz et al., 1994; Alam et al., 1995a; Guzman-Marin et al., 2000; Methipara et al., 2003). These findings suggest the possibility that the WSN of the POA do have an inhibitory action on the arousal promoting neurons. Results from the POA warming studies indicate a
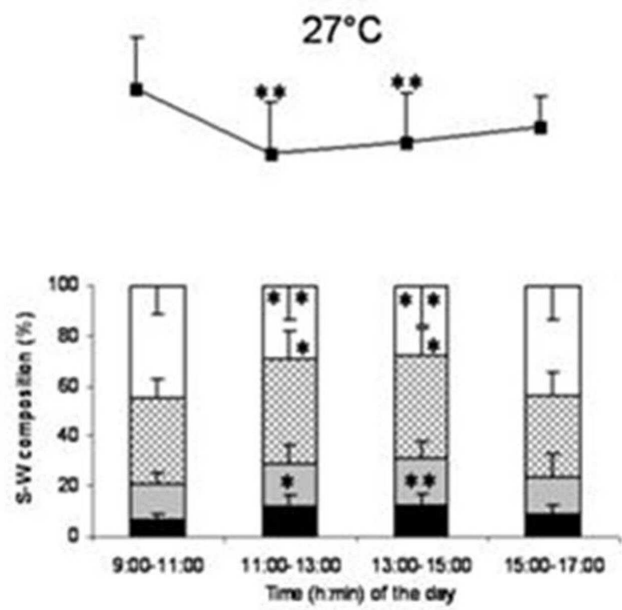

FIGURE 2 | Sleep-wake stages (bar diagram) and body temperature (line diagram) in $2 \mathrm{~h}$ bin at 27 and $30^{\circ} \mathrm{C}$ ambient temperature. Sleep parameters and body temperature recording for $6 \mathrm{~h}$ (11:00-17:00 hours) at 27 and $30^{\circ} \mathrm{C}$ was preceded by $2 \mathrm{~h}$ baseline recording (9:00-11:00 hours) at $27^{\circ} \mathrm{C}$. $X$-axis shows the time of the day. $Y$-axis shows percentage time (mean $\pm S D$ ) of recordings (bar diagram)
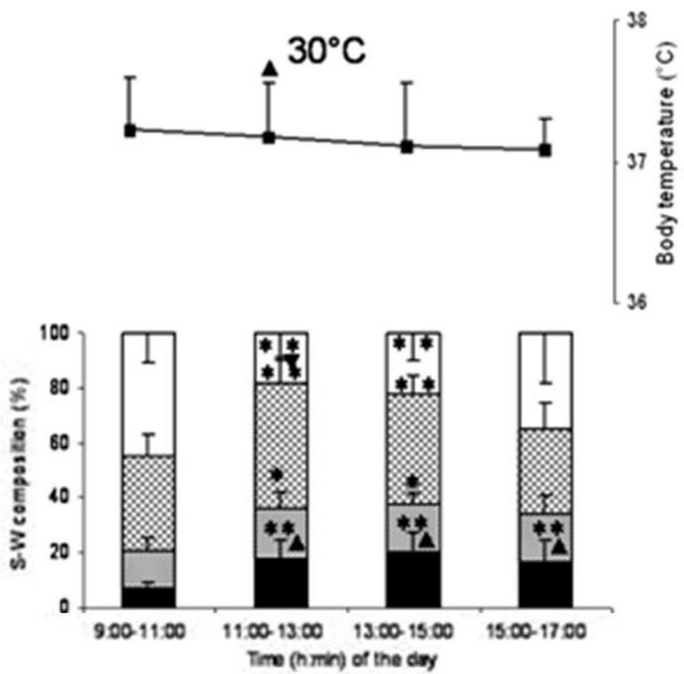

in sleep-wakefulness and body temperature (line diagram). ${ }^{*} p<0.05$,

${ }^{*} p<0.01$, shows significance of change in each $2 \mathrm{~h}(11: 00-13: 00$, 13:00-15:00, and 15:00-17:00 hours) compared to baseline

(9:00-11:00 hours) data. ${ }^{\star} p<0.05$, shows significance of change in three $2 \mathrm{~h}$ bin (11:00-13:00, 13:00-15:00, and 15:00-17:00 hours) at $30^{\circ} \mathrm{C}$ compared to time matched bin of $27^{\circ} \mathrm{C}$. 
homeostatic regulation by which sleep is promoted during mild rise of body temperature, which not only plays a thermoregulatory role but also serves as a protective mechanism to prevent the animal from venturing into a hostile thermal environment.

\section{ROLE OF THERMORECEPTORS IN AMBIENT TEMPERATURE RELATED SLEEP CHANGES}

Based on the results of several studies it is concluded that both ambient and body temperatures profoundly influence sleep architecture (Horne and Staff, 1983; Obal et al., 1983; Szymusiak and Satinoff, 1984; Horne and Shackell, 1987; Shapiro et al., 1989; McGinty and Szymusiak, 1990; Morairty et al., 1993; Thomas and Kumar, 2000; Kumar et al., 2009). The thermoregulatory pathway which initiates heat and cold defense response is conveyed by skin thermoreceptors, en route dorsal horn, and parabrachial nuclei, to the POA (Nakamura, 2011). It is natural to assume that changes in sleep brought about by $T_{\mathrm{amb}}$ is sensed and mediated by thermoreceptors. The roles of peripheral and central thermoreceptors have been investigated in order to get an insight into the role of afferent thermal inputs, from periphery and core, in the promotion of sleep. Capsaicin has been traditionally used for destruction of thermoreceptors and WSN. In an earlier report, sleep-wakefulness was studied in normal and capsaicin-treated rats when they were placed at $T_{\mathrm{amb}}$ of 22 and $29^{\circ} \mathrm{C}$ (Obal et al., 1983). There was an increase in sleep at the elevated temperature of $29^{\circ} \mathrm{C}$, though REM sleep showed only a minor increase. The ambient temperature related increase in NREM sleep was not seen after destruction of peripheral and central warm receptors.

There are different experimental models to explore the relative role of peripheral and central thermoreceptors in the $T_{\mathrm{amb}}$ mediated sleep mechanism. In the first model, systemic administration of capsaicin in high doses destroys both peripheral and central warm receptors. In the second model, local application in the POA destroys WSN in this region only. In the third model, when neonatal rats are treated with capsaicin, their peripheral thermosensitivity is lost, while their central thermoregulatory neurons are preserved (Hajós et al., 1983). As mentioned earlier, when the rats were exposed to 27,30 , and $33^{\circ} \mathrm{C}$, the rats had maximum sleep at $30^{\circ} \mathrm{C}$, though they preferred to stay at $27^{\circ} \mathrm{C}$. When both peripheral and central warm receptors, were destroyed in these rats (by systemic administration of capsaicin), the selective increase in REM sleep at $30^{\circ} \mathrm{C}$ was not seen (Kumar et al., 2012). When peripheral warm receptors were selectively destroyed by neonatal treatment of capsaicin, the central warm receptors were able to mediate an increase in TST with increasing $T_{\mathrm{amb}}$, even in the absence of peripheral warm receptors (Gulia et al., 2005). This shows that the central WSN mediate the warm $T_{\mathrm{amb}}$ related increase in SWS and REM sleep. When WSN of the POA were destroyed by local injection of capsaicin, the increase in REM sleep and SWS at $30^{\circ} \mathrm{C}$ was not observed. SWS peak was brought down to $27^{\circ} \mathrm{C}$, and REM sleep peak shifted to a higher temperature of $33^{\circ} \mathrm{C}$, in these animals. The study clearly indicates that WSN of the POA mediate the increase in SWS, at temperatures higher than preferred $T_{\mathrm{amb}}$. It also showed that the REM sleep generation is under some sort of inhibitory control of the WSN of the POA. The study shows that the neurons of the POA play a key role in regulating sleep as per homeostatic requirement (Kumar et al., 2011).

\section{INTERLINIKING THERMOREGULATION AND SLEEP}

Much attention has been given to the physiological role of the POA, because of its ability to control thermoregulation and sleep. Many of the observations cited earlier support the hypothesis that sleep is modulated by thermosensitive neurons of the POA (Parmeggiani et al., 1975; Obal et al., 1983; McGinty and Szymusiak, 1990). Although this relationship has drawn considerable interest, it is still not known whether there is a "cause and effect" relationship or whether these changes are merely coincidental. There are some direct and indirect observations that give answers to this fundamental question. Single unit studies clearly demonstrate that the POAH neurons, likely to be responsible for thermoregulation, are influenced by vigilance states (Alam et al., 1995a). The thermosensitivity of the POA neurons are reduced during SWS as compared to wakeful state (Parmeggiani et al., 1987). During SWS, a majority of WSN of POAH exhibit increased discharge rate. CSN exhibit less discharge during SWS and decreased thermosensitivity. The activation of these sleep-related WSN and inhibition of wake related CSN may play a role in the onset and regulation of SWS (Alam et al., 1995b). It could also be assumed that the POAH neurons which are responsible for sleep-wake modulations are thermosensitive (Szymusiak and McGinty, 1985; McGinty and Szymusiak, 2003). Most of the assertions that thermoreceptive elements control sleep regulation are based on results obtained from warming and cooling of the POAH neurons using thermodes. Warming of the POAH has been shown to suppress activity in the wake related magnocellular $\mathrm{BF}$ and posterior lateral hypothalamus of cats (Krilowicz et al., 1994; Alam et al., 1995a,b) and dorsal raphe and lateral hypothalamus of rats (Guzman-Marin et al., 2000; Methipara et al., 2003). These results suggest that WSN of the POAH may play a key role in the regulation of SWS sleep (Alam et al., 1995a,b; McGinty and Szymusiak, 2003). Evidences chemical stimulation studies in support of alteration in sleep by thermoregulatory system is described in detail elsewhere (Kumar, 2005). So, the modulation of sleep-wake state by POAH thermosensitive neurons must be viewed as a distinct possibility.

\section{DIURNAL TEMPERATURE RHYTHM INFLUENCES AND SLEEP PROPENSITY}

The influence of diurnal temperature rhythm on sleep is best studied in man. Both skin temperature and core body temperature show a day-night rhythm. In humans, the core temperature is relatively low during sleep at night and it is relatively high during waking period during day time. Skin temperature also exhibits a circadian rhythm, but its changes are reciprocal to that of the core body temperature rhythm (van Someren, 2006). The core body temperature and sleep propensity are negatively related, whereas skin temperature and sleep are positively related (Magnussen, 1939; Lack and Lushington, 1996). The degree of heat loss at the skin of the hands and feet is said to be the best physiologic predictor for a rapid sleep onset (Kräuchi et al., 1999, 2000). It was suggested that that autonomous thermoregulatory changes in core body temperature and skin temperature could act as an input signal to modulate neuronal activity in sleep-regulating brain areas (van Someren, 2000). The activities of thermosensitive neurons in the POAH, are suggested to be modulated more strongly by changes in skin temperature, than by changes in core temperature (Boulant and Bignall, 1973). Manipulation of the skin temperature 
within the TNZ can modulate sleepiness and sleep depth, even without activating thermoregulatory responses (Raymann et al., 2008). Even mild changes in skin temperature that occur during normal sleep can have an effect on sleep propensity not only in young adults but also in elderly subjects (Raymann and Van Someren, 2008).

\section{SOME TEMPERATURE RELATED CHANGES IN SLEEP THAT MAY NOT INVOLVE THERMORECEPTORS}

While emphasizing the role of thermoreceptors in sleep regulation, it should not be forgotten that the increase in sleep, especially REM sleep, on increasing the $T_{\mathrm{amb}}$ from 18 to $30^{\circ} \mathrm{C}$, is not abolished by destructions of both peripheral and central WSN (Figure 3). Moreover, REM sleep was increased even at $T_{\mathrm{amb}}$ of $33^{\circ} \mathrm{C}$ after WSN of the POA were destroyed. This indicates that we cannot attribute all the $T_{\mathrm{amb}}$ related changes in sleep to the POA thermoreceptors.

Though sleep-wake modulation by thermosensitive neurons is almost certain, it is difficult to assert that they are only responsible for temperature related sleep promotion. Manipulation of POAH temperature will affect not only thermosensitive neurons that are responsible for thermoregulation, but also those non-thermosensitive neurons which are responsible for sleep promotion. Though POAH thermosensitive neurons have a $\mathrm{Q} 10>3$, the influence of local warming on non-thermosensitive sleeppromoting neurons cannot be excluded. Moreover, sleep is promoted by not only the POA but also by several other structures at multiple neuronal levels. There are also extra-preoptic sites for thermoregulation. As mentioned earlier, there was decrease in deeper stages of sleep (deep SWS and REM sleep) after the POA lesion (John et al., 1994; John and Kumar, 1998). The changes in S-W were also studied during exposure to a different ambient temperature after the destruction of the POA neurons by NMDA. Though the MPOA neuronal destruction produced a decrease in sleep, there was linear increase in sleep at higher temperature (Thomas and Kumar, 2000). In normal rats there was increase in long durations SWS episodes. But, on the other hand, in the lesioned rats, $T_{\mathrm{amb}}$ of $30^{\circ} \mathrm{C}$ produced an increase in the number of short durations SWS episodes. It has been hypothesized that POA is important for sleep maintenance as it was the sleep duration which was primarily affected by the POA lesion (John and Kumar, 1998). The warm environment could increase the amount of sleep even after the POA lesion but the higher ambient temperature was more efficient in initiating sleep rather than maintaining it. In other words the ability to maintain SWS was affected after the POA lesion and this ability could not be restored by exposure to a warmer environment. The findings indicate that the POA promotes sleep maintenance and for improves the quality of sleep at
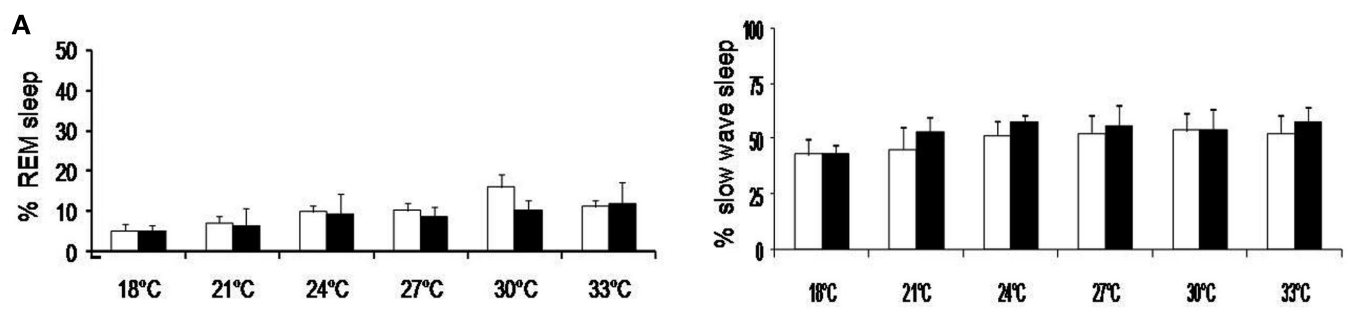

B

Peripheral and central warm receptors destroyed
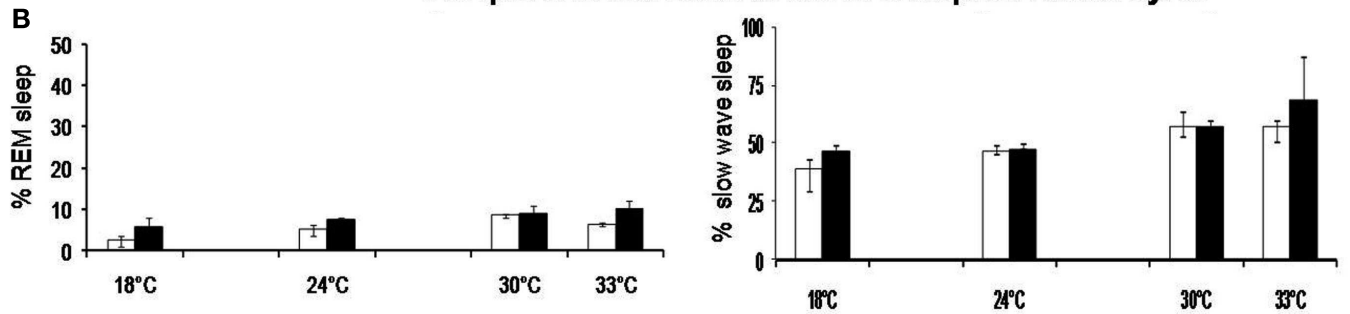

Peripheral warm receptors destroyed
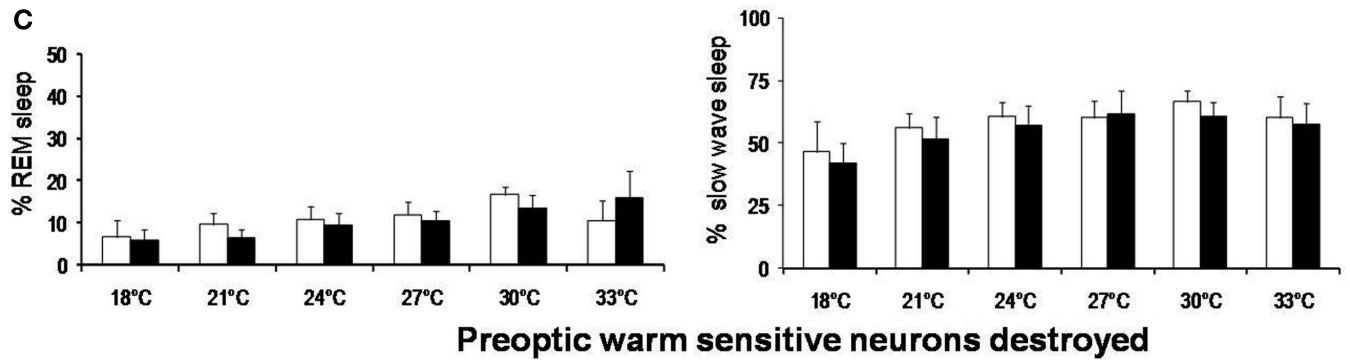

FIGURE 3 | Rapid eye movement sleep and slow wave sleep (\% mean $\pm S D$ ) at different ambient temperature in rats before and after destruction of $(A)$ peripheral and central warm receptors, $(B)$ only peripheral warm receptors, and (C) only preoptic warm sensitive neurons. ${ }^{*} p<0.05$, significance of change at different ambient temperature compared with $27^{\circ} \mathrm{C} .{ }^{\dagger} p<0.05$, significance of change at different ambient temperature compared with $18^{\circ} \mathrm{C}+p<0.05,{ }^{\ddagger} p<0.01$, significance of change between before and after destruction. 
higher $T_{\mathrm{amb}}$. But it should be recognized that that the $T_{\mathrm{amb}}$ has a sleep promotion role which may not involve thermoregulatory mechanism.

\section{CONCLUDING REMARIKS}

Results from our laboratory and those from others collectively suggest that the ambient and body temperatures are important determinants of both quantity and quality of sleep. There is now growing evidence to suggest that sleep is auto-regulatory. But this auto-regulatory mechanism is constantly modulated by

\section{REFERENCES}

Alam, M. N., Szymusiak, R., and McGinty, D. (1995a). Local preoptic/anterior hypothalamic warming alters spontaneous and evoked neuronal activity in the magnocellular basal forebrain. Brain Res. 696, 221-230.

Alam, M. N., McGinty, D., and Szymusiak, R. (1995b). Preoptic/anterior hypothalamic neurons: thermosensitivity in rapid eye movement sleep. Am. J. Physiol. 269, R1250-R1257.

Alföldi, P., Rubicsek, G., Cserni, G., and Obál, F. Jr. (1990). Brain and core temperatures and peripheral vasomotion during sleep and wakefulness at various ambient temperatures in the rat. Pflugers Arch. 417, 336-341.

Baker, F. C., Angara, C., Szymusiak, R., and McGinty, D. (2005). Persistence of sleep-temperature coupling after suprachiasmatic nuclei lesions in rats. Am. J. Physiol. Regul. Integr. Comp. Physiol. 289, R827-R838.

Bligh, J., and Johnson, K. G. (1973). Glossary of terms for thermal physiology. J. Appl. Physiol. 35, 941-961.

Boulant, J. A. (1981). Hypothalamic mechanisms in thermoregulation. Fed. Proc. 40, 2843-2850.

Boulant, J. A., and Bignall, K. E. (1973). Hypothalamic neuronal responses to peripheral and deep-body temperatures. Am. J. Physiol. 225, 1371-1374.

Boulant, J. A., and Dean, J. B. (1986). Temperature receptors in the central nervous system. Annu. Rev. Physiol. 48, 639-654.

Boulant, J. A., and Hardy, J. D. (1974). The effect of spinal and skin temperatures on the firing rate and thermosensitivity of preoptic neurones. J. Physiol. 240, 639-660.

Chen, X. M., Hosono, T., Yoda, T., Fukuda, Y., and Kanosue, K. (1998). Efferent projection from the preoptic area for the control of nonshivering thermogenesis in rats. J. Physiol. (Lond.) 512, 883-892.

Clarkson, D. P., Schatte, C. L., and Jordan, J. P. (1972). Thermal neutral temperature of rats in heliumoxygen, argon-oxygen, and air. Am. J. Physiol. 222, 1494-1498.

Gong, H., Szymusiak, R., King, J., Steininger, T., and McGinty, D. (2000). Sleep-related c-Fos protein expression in the preoptic hypothalamus: effects of ambient warming. Am. J. Physiol. 279, R2079-R2088.

Gordon, C. J. (1987). Relationship between preferred ambient temperature and autonomic thermoregulatory function in rat. Am. J. Physiol. 252, R1130-R1137.

Gulia, K. K., Mallick, H. N., and Kumar, V. M. (2005). Ambient temperature related sleep changes in rats neonatally treated with capsaicin. Physiol. Behav. 85, 414-418.

Guzman-Marin, R., Alam, M. N., Drucker-Colin, R., and McGinty, D. (2000). Discharge modulation of rat dorsal raphe neurons during sleep and waking: effects of preoptic/basal forebrain warming. Brain Res. 875, 23-24.

Hajós, M., Obál, F. Jr., Jancsó, G., and Obál, F. (1983). The capsaicin sensitivity of the preoptic region is preserved in adult rats pretreated as neonates, but lost in rats pretreated as adults. Naunyn Schmiedebergs Arch. Pharmacol. 324, 219-222.

Hammel, H. T. (1960). Regulation of internal body temperature. Annu. Rev. Physiol. 30, 641-710.

Haskell, E. H., Palca, J. W., Walker, J. M., and Berger, R. J., Heller, H. C. (1981). The effects of high and low ambient temperatures on human sleep stages. Electroencephalogr. Clin. Neurophysiol. 51, 494-501.

Hayaishi, O. (1991). Molecular mechanisms of sleep-wake regulation:roles of prostaglandins D2 and E2. FASEB J. 5, 2575-2581.

Herrington, L. P. (1940). The heat regulation of small laboratory animal at various environmental temperatures. Am. J. Physiol. 129, 123-139.

Horne, J. A., and Shackell, B. S. (1987). Slow wave sleep elevations after body heating: proximity to sleep and effects of Aspirin. Sleep 10, 383-392.

several factors, as per homeostatic requirement. Sleep-wakefulness is influenced by external input and internal feedback. In this context, thermoregulatory inputs are extremely important, as they can not only modulate sleep, but can also reset thermoregulation to ensure sleep homeostasis. Sleep and vigilance states oscillate as a result of dynamic interaction of wide spread neuronal network. Almost all the brain segments contribute toward modulating the sleep-wake cycle as per requirement. BF input, especially those related thermoregulation, forms an important component of this modulating neuronal network.

Horne, J. A., and Staff, L. H. (1983). Exercise and sleep: body-heating effects. Sleep 6, 36-46.

Imai-Matsumura, K., Matsumura, K. and Nakayama, T. (1984). Involvement of ventromedial hypothalamus in brown adipose tissue thermogenesis induced by preoptic cooling in rats. Jpn. J. Physiol. 34, 939-943.

John, J., and Kumar, V. M. (1998). Effect of NMDA lesion of the medial preoptic neurons on sleep and other functions. Sleep 21, 587-598.

John, J., Kumar, V. M., Gopinath, G., Ramesh, V., and Mallick, H. N. (1994). Changes in sleepwakefulness after kainic acid lesion of the preoptic area in rats. Jpn. J. Physiol. 44, 231-242.

John, J., Kumar, V. M., and Gopinath, G. (1998). Recovery of sleep after fetal preoptic transplantation in medial preoptic area lesioned rats. Sleep 15 , 601-606.

Kanosue, K., Nakayama, T., Tanaka, H. Yanase, M., and Yasuda, H. (1990). Modes of action of local hypothalamic and skin thermal stimulation on salivary secretion in rats. J. Physiol. 424, 459-471.

Kanosue, K., Yanase-Fujiwara, M., and Hosono, T. (1994). Hypothalamic network for thermoregulatory vasomotor control. Am. J. Physiol. Regul. Integr. Comp. Physiol. 267, R283R288.

Khubchandani, M., Jagannathanm, N. R., Mallick, H. N., and Kumar, V. M. (2005). Functional MRI shows activation of the medial preoptic area during sleep. Neuroimage 26, 29-35.

Kräuchi, K., Cajochen, C., Werth, E., and Wirz-Justice, A. (1999). Warm feet promote the rapid onset of sleep. Nature 401, 36-37.

Kräuchi, K., Cajochen, C., Werth, E., and Wirz-Justice, A. (2000). Functional link between distal vasodilatation and sleep-onset latency? Am. J. Physiol. 278, R741-R748.

Krilowicz, B. L., Szymusiak, R., and McGinty, D. (1994). Regulation of posterior lateral hypothalamic arousal related neuronal discharge by preoptic anterior hypothalamic warming. Brain Res. 668, 30-38.

Kumar, D., Kumar, V. M., and Mallick, H. N. (2011). Warm sensitive neurons of preoptic area regulate ambient temperature related changes in sleep. Indian J. Physiol. Pharmacol. 55, 262-271.

Kumar, D., Kumar, V. M., and Mallick, H. N. (2012). Ambient temperature dependent thermoregulatory role of REM sleep. J. Therm. Biol. 37, 392396.

Kumar, D., Mallick, H. N., and Kumar, V. M. (2009). Ambient temperature that induces maximum sleep in rats. Physiol. Behav. 98, 186-191.

Kumar, V. M. (1999). Role of the preoptic area in the inter-relationship between thermoregulatory and sleep regulatory mechanisms. Sleep Hypn. 1, 1-9.

Kumar, V. M. (2005). Body temperature and sleep: are they controlled by the same mechanism? Sleep Biol. Rhythms 2, 103-124.

Kumar, V. M. (2010). Sleep is neither a passive nor an active phenomenon. Sleep Biol. Rhythms 8, 163-169.

Kumar, V. M., John, J., Govindaraju, V., Khan, N. A., and Raghunathan, P. (1996). Magnetic resonance imaging of NMDA induced lesion of the medial preoptic area and changes in sleep, temperature and sex behaviour. Neurosci. Res. 24, 207-214.

Kumar, V. M., and Khan, N. A. (1998). Role of the preoptic neurons in thermoregulation in rats. Arch. Clin. Exp. Med. 7, 24-27.

Lack, L. C., and Lushington, K. (1996). The rhythms of human sleep propensity and core body temperature. J. Sleep Res. 5, 1-11.

Libert, J. P., Bach, V., Johnson, L. C., Ehrhart, J., Wittersheim, G., and Keller, D. (1991). Relative and combined effects of heat and noise exposure on sleep in humans. Sleep 14 21-31.

Libert, J. P., Di Nisi, J., Fukuda, H., Muzet, A., Ehrhart, J., and Amoros, C. (1988). Effect of continuous heat exposure on sleep stages in humans. Sleep 11, 195-209. 
Lu, J., Greco, M., Shiromani, P., and Saper, C. (2000). Effect of the lesion of the ventrolateral preoptic nucleus in NREM and REM sleep. during rapid eye movement sleep. J. Neurosci. 20, 3830-3842.

Magnussen, G. (1939). Vasomotorische Veränderingen in den Extremitäten im Verhältnis zu Schlaf und Schlafbereitschaft. Acta Psychiatr. Neurol. 14, 39-54.

Mahapatra, A. P. K., Mallick, H. N., and Kumar, V. M. (2005). Changes in sleep on chronic exposure to warm and cold ambient temperatures. Physiol. Behav. 84, 287-294.

McGinty, D., and Szymusiak, R. (1990). Keeping cool: a hypothesis about the mechanisms and functions of slow-wave sleep. Trends Neurosci. 13, 480-487.

McGinty, D., and Szymusiak, R. (2003). Hypothalamic regulation of sleep and arousal. Front. Biosci. 8 , 1074-1083.

McGinty, D. J., and Sterman, M. B. (1968). Sleep suppression after basal forebrain lesions in the cat. Science 160, 1253-1255.

Methipara, M. A., Alam, M. N., Szymusiak, R., and McGinty, D. (2003). Preoptic area warming inhibits wakeactive neurons in the periformical lateral hypothalamus. Brain Res. 960 , 165-173.

Morairty, S. R., Szymusiak, R., Thomson, D., and McGinty, D. J. (1993). Selective increases in non-rapid eye movement sleep following whole body heating in rats. Brain Res. 617 , 10-16.

Moruzzi, G. (1972). The sleep-waking cycle. Ergeb. Physiol. 64, 1-165.

Nakamura, K. (2011). Central circuitries for body temperature regulation and fever. Am. J. Physiol. Regul. Integr. Comp. Physiol. 301, R1207-R1228.

Nakayama, T., Eisenman, J. S., and Hardy, J. D. (1961). Unit activity in anterior hypothalamus during local heating. Science 134, 560-561.

Nakayama, T., Hammel, H. T., Hardy, J. D., and Eisenman, J. S. (1963). Thermal stimulation of electrical activity of single units of the preoptic region. Am. J. Physiol. 204, 1122-1126.

Nauta, W. J. H. (1946). Hypothalamic regulation of sleep in rats: an experimental study. J. Neurophysiol. 9, 285-316.

Obal, F. Jr., Rubicsek, G., Alfoldi, P., Sary, G., and Obal, F. (1985). Changes in the brain and core temperatures in relation to the various arousal states in rats in the light and dark periods of the day. Pflugers Arch. 404, 73-79.
Obal, F. Jr., Tobler, I., and Borbely, A. A. (1983). Effect of ambient temperature on the 24-hour sleep-wake cycle in normal and capsaicin-treated rats. Physiol. Behav. 30, 425-430.

Osborne, A. R., and Refinetti, R. (1995). Effects of hypothalamic lesions on the body temperature rhythm of the golden hamster. Neuroreport 6, 2187-2192.

Parmeggiani, P. L., Cevolani, D., Azzaroni, A., and Ferrari, G. (1987). Thermosensitivity of anterior hypothalamic preoptic neurons during the waking-sleeping cycle: a study in brain functional states. Brain Res. $415,79-89$.

Parmeggiani, P. L., and Rabini, C. (1970). Sleep and environmental temperature. Arch. Ital. Biol. 108, 369-387.

Parmeggiani, P. L., Rabini, C., and Cattalani, M. (1969). Sleep phases at low environmental temperature. Arch. Sci. Biol. (Bologna) 53, 277-290.

Parmeggiani, P. L., Agnati, L. F., Zamboni, G., and Ciani, T. (1975). Hypothalamic temperature during the sleep cycle at different ambient temperatures. Electroencephalogr. Clin. Neurophysiol. 38, 589-596.

Poole, S., and Stephenson, J. D. (1977). Body temperature regulation and thermoneutrality in rats. Q. J. Exp. Physiol. Cogn. Med. Sci. 62, 143-149.

Porkka-Heiskanen, T., Strecker, R. E., Thakkar, M., Bjorkum, A. A., Greene, R. W., and McCarley, R. W. (1997). Adenosine: a mediator of the sleepinducing effects of prolonged wakefulness. Science 276, 1265-1268.

Ray, B., Mallick, H. N., and Kumar V. M. (2004). Changes in thermal preference, sleep-wakefulness, body temperature and locomotor activity of rats during continuous recording for 24 hours. Behav. Brain Res. 154, 519-526.

Ray, B., Mallick, H. N., and Kumar, V. M. (2005). Changes in sleepwakefulness in the medial preoptic area lesioned rats: role of thermal preference. Behav. Brain Res. 158, 43-52.

Raymann, R. J., and Van Someren, E. J. (2008). Diminished capability to recognize the optimal temperature for sleep initiation may contribute to poor sleep in elderly people. Sleep 9, 1301-1309.

Raymann, R. J. E. M., Swaab, D. F., and Van Someren, E. J. W. (2008). Skin deep: enhanced sleep depth by cutaneous temperature manipulation. Brain 131, 500-513.
Romanovsky, A. A., Ivanov, A. I., and Shimansky, Y. P. (2002). Selected contribution: ambient temperature for experiments in rats: a new method for determining the zone of thermal neutrality. J. Appl. Physiol. 92, 2667-2679.

Rosenthal, M. S., and Vogel, G. (1991). Prolonged temperature increase produces prolonged REM sleep increase in Rat. Sleep Res. 20A, 513.

Sakaguchi, S., Glotzbach, S. F., and Heller, H. C. (1979). Influence of hypothalamic and ambient temperatures on sleep in kangaroo rats. Am. J. Physiol. 237, R80-R88.

Schmidek, W. R., Hoshino, K., Schmidek, M., and Timo-Iaria, C. (1972). Influence of environmental temperature on the sleep-wakefulness cycle in the rat. Physiol. Behav. 8, 363-371.

Shapiro, C. M., Allan, M., Driver, H., and Mitchell, D. (1989). Thermal load alters sleep. Biol. Psychiatry 26, 736-740.

Sherin, J. E., Shiromani, P. J., McCarley, R. W., and Saper, C. B. (1996). Activation of ventrolateral preoptic neurons during sleep. Science 271 216-219.

Srividya, R., Mallick, H. N., and Kumar, V. M. (2004). Sleep changes produced by destruction. Neuroreport 15, 1831-1835.

Srividya, R., Mallick, H. N., and Kumar, V. M. (2006). Differences in the effects of medial, and lateral preoptic lesions on thermoregulation, and sleep in rats. Neuroscience 139 853-864.

Sterman, M. B., and Clemente, C D. (1962). Forebrain inhibitory mechanisms: sleep patterns induced by basal forebrain stimulation in the behaving cat. Exp. Neurol. 6, 103-117.

Szymusiak, R., and McGinty, D. (1985). Sleep-related neuronal discharge in the basal forebrain of cats. Brain Res. 370, 82-92.

Szymusiak, R., and McGinty, D. (1986). Sleep suppression following kainic acid-induced lesions of the basal forebrain. Exp. Neurol. 94, 598-614.

Szymusiak, R., and Satinoff, E. (1981). Maximal REM sleep time defines a narrower thermoneutral zone than does minimal metabolic rate. Physiol. Behav. 26, 687-690.

Szymusiak, R., and Satinoff, E. (1982). Acute thermoregulatory effects of unilateral electrolytic lesions of the medial and lateral preoptic area in rats. Physiol. Behav. 28, 161-170.

Szymusiak, R., and Satinoff, E. (1984). Ambient temperatyre dependence of sleep disturbance produced by basal forebrain in rats. Brain Res. Bull. 12, 295-305.

Thomas, T. C., and Kumar, V. M. (2000). Effect of ambient temperature on sleep-wakefulness in normal and medial preoptic area lesioned rats. Sleep Res. Online 3, 141-145.

Thomas, T. C., and Kumar, V. M. (2002). Effect of ambient temperature on brain temperature and sleepwakefulness in medial preoptic area lesioned rats. Indian J. Physiol. Pharmacol. 46, 287-297.

Valatx, J. L., Roussel, B., and Cure, M. (1973). Sleep and cerebral temperature in rat during chronic heat exposure. Brain Res. 55, 107-122.

van Someren, E. J. W. (2000). More than a marker, interaction between the circadian regulation of temperature and sleep, age-related changes, and treatment possibilities. Chronobiol. Int. 17, 313-354.

van Someren, E. J. W. (2006). Mechanisms and functions of coupling between sleep and temperature rhythms. Prog. Brain Res. 153, 309-324.

von Economo, C. (1930). Sleep as a problem of localization. J. Nerv. Ment. Dis. 71, 249-259.

Conflict of Interest Statement: The authors declare that the research was conducted in the absence of any commercial or financial relationships that could be construed as a potential conflict of interest.

Received: 11 April 2012; paper pending published: 18 April 2012; accepted: 09 June 2012; published online: 27 June 2012.

Citation: Mallick $H N$ and Kumar $V M$ (2012) Basal forebrain thermoregulatory mechanism modulates autoregulated sleep. Front. Neur. 3:102. doi: 10.3389/fneur.2012.00102

This article was submitted to Frontiers in Sleep and Chronobiology, a specialty of Frontiers in Neurology.

Copyright $\odot 2012$ Mallick and Kumar. This is an open-access article distributed under the terms of the Creative Commons Attribution Non Commercial License, which permits non-commercial use, distribution, and reproduction in other forums, provided the original authors and source are credited. 